\title{
Breast cancer in Iran: need for greater women awareness of warning signs and effective screening methods
} Ali Montazeri*1,4, Mariam Vahdaninia1, Iraj Harirchi², Amir Mahmood Harirchi ${ }^{3}$, Akram Sajadian ${ }^{4}$, Fatemeh Khaleghi ${ }^{4}$, Mandana Ebrahimi ${ }^{4}$, Shahpar Haghighat ${ }^{4}$ and Soghra Jarvandi ${ }^{4}$

\author{
Address: ${ }^{1}$ Iranian Institute for Health Sciences Research (IHSR), ACECR, Tehran, Iran, ${ }^{2}$ Tehran University of Medical Sciences, Tehran, Iran, \\ ${ }^{3}$ University of Social Welfare and Rehabilitation Sciences, Tehran, Iran and ${ }^{4}$ Iranian Centre for Breast Cancer (ICBC), ACECR, Tehran, Iran \\ Email: Ali Montazeri* - montazeri@acecr.ac.ir; Mariam Vahdaninia - vahdaninia@acecr.ac.ir; Iraj Harirchi - harirchi@tums.ac.ir; \\ Amir Mahmood Harirchi - harirchi@uswr.ac.ir; Akram Sajadian - sajadian@icbc.ac.ir; Fatemeh Khaleghi - khaleghi@icbc.ac.ir; \\ Mandana Ebrahimi - ebrahimi@icbc.ac.ir; Shahpar Haghighat - haghighat@icbc.ac.ir; Soghra Jarvandi - jarvandi@icbc.ac.ir \\ * Corresponding author
}

Published: 20 December 2008

Asia Pacific Family Medicine 2008, 7:6 doi:10.1 186/1447-056X-7-6

This article is available from: http://www.apfmj.com/content/7/1/6

(c) 2008 Montazeri et al; licensee BioMed Central Ltd.

This is an Open Access article distributed under the terms of the Creative Commons Attribution License (http://creativecommons.org/licenses/by/2.0), which permits unrestricted use, distribution, and reproduction in any medium, provided the original work is properly cited.
Received: 12 August 2008

Accepted: 20 December 2008

\begin{abstract}
Background: Breast cancer remains an important public health problem. This study aimed to investigate about female knowledge of breast cancer and self-reported practice of breast self-examination in Iran.

Methods: This was a population-based survey carried out in Tehran, Iran. Data were collected via a structured questionnaire containing 15 questions on demographic status, history of personal and family breast problems, subjective knowledge about breast cancer covering its symptoms, the screening methods and practice of breast self-examination (BSE). A trained female nurse interviewed each respondent. Analysis included descriptive statistics and the Chi-squared test where necessary.

Results: A total of I 402 women were interviewed. The mean age of respondents was 43.4 (SD = 14.4) years; most were married $(85 \%)$, and without any personal $(94 \%)$ and family history $(90 \%)$ of breast problems. It was found that $64 \%$ of the respondents were familiar with breast cancer and $61 \%(n=85 \mathrm{I})$ believed that 'the disease is relatively common among women in Iran'. Most women (44\%) perceived a painless mass as a breast cancer symptom. Overall, $61 \%$ of the respondents stated that they knew about breast cancer screening programs and most indicated that electronic media (television 34\% and radio 14\%) were their source of information. Only 17\% of women said that 'they were conducting regular breast self-examination'. The main reason for women not doing breast self-examination was due to the fact that they did not know how to do it (64\%). The findings indicated that performing breast self-examination is significantly related to: age, marital status, education, knowledge of breast cancer and knowledge about breast cancer screening programs $(P<0.05)$, but not to personal $(P=0.2)$ and family $(P=0.7)$ history of breast problems.

Conclusion: This descriptive study provides useful information that could be utilized by both researchers and those involved in public health programmes. The findings indicated that the women awareness of breast cancer warning signs (painless lump, retraction of nipple, and bloody discharge) and effective screening methods i.e. clinical examination, and mammography were very inadequate. Thus, health education programmes to rectify the lack of women awareness is urgently needed. Indeed the focus of primary health care providers should be to raise awareness about breast care among women and to encourage them to report any unusual changes in their breasts to their family or care physicians.
\end{abstract}




\section{Background}

Breast cancer is one of the most common cancers among females worldwide. Global statistics show the annual incidence of breast cancer is increasing and this is occurring more rapidly in countries with a low incidence rate of breast cancer $[1,2]$. It has been reported that each year over 1.15 million women worldwide are diagnosed with breast cancer and 502,000 die from the disease [3]. In Iran the incidence of the disease is rising, patients present with advanced stage of disease and they are relatively younger (about 10 years) than their western counterparts $[4,5]$. The latest formal information on age-specific incidence rate of female breast cancer per 100,000 population in Iran is presented in Table 1[6].

Early detection of breast cancer plays the leading role in reducing mortality rates and improving the patients' prognosis [7]. The recommended screening methods for early detection of this fatal disease are: mammography, clinical breast examination and breast self-examination (BSE).

Mammography is an expensive modality for screening and needs several requisites including logistic and professional manpower before its implementation. Randomized trials comparing mammography with no mammography screening found that at best women might benefit a $15 \%$ relative risk reduction in mortality from mammography [8]. In addition it has been shown

Table I: Age-specific incidence rate of female breast cancer per 100.000 population in Iran in 2005-2006 $(n=598 I)$

\begin{tabular}{ll}
\hline & Incidence rate \\
\hline $\begin{array}{l}\text { Age groups (years) } \\
\text { I5-19 }\end{array}$ & \\
$20-24$ & 0.02 \\
$25-29$ & 0.78 \\
$30-34$ & 5.91 \\
$35-39$ & 14.74 \\
$40-44$ & 33.14 \\
$45-49$ & 47.90 \\
$50-54$ & 74.03 \\
$55-59$ & 74.31 \\
$60-64$ & 69.28 \\
$65-69$ & 69.09 \\
$70-74$ & 48.58 \\
$75-79$ & 43.71 \\
$80-84$ & 44.53 \\
$\geq 85$ & 58.45 \\
Crude rate & 22.09 \\
Age specific rate (weighted) & 17.44 \\
\hline Type of breast cancer & 23.16 \\
Infiltrating ductal carcinoma & $\%$ \\
Infiltrating lobular carcinoma & 80 \\
Medullary carcinoma & 5.9 \\
\hline
\end{tabular}

that for women under the age of 50 years mammography screening is ineffective [9].

Clinical breast examination is relatively simple and inexpensive but the exact benefit of this screening modality in reducing mortality is yet to be established. It is argued that in diagnosis of breast cancer by screening the shift should be to the point that will cost least both in human and financial terms and be effective in reducing mortality, and that clinical breast examination would be able to fulfill this [10]. However, it has been shown that clinical breast examination could only detect about $60 \%$ of breast cancers detected by mammography as well as some breast cancers not detected by mammography [11]. Recent estimates suggest that clinical breast examination has a sensitivity of about $54 \%$ and specificity of about $94 \%$ [12].

Unlike to mammography and clinical breast examination, BSE is simple, inexpensive, low in technology, teaching is possible to both health professionals and women and more importantly raises awareness about breast cancer in women. It is argued that in many countries, especially in developing countries, BSE may be the only realistic approach to the early detection of breast cancer [10]. However there is no clear evidence to support the efficacy of performing routine BSE in early detection and cause specific mortality due to breast cancer. While a number of studies have found that BSE has improved early detection and reduced mortality $[13,14]$, data from a randomized trial in Russia has suggested that there is no significant difference in those who perform BSE and those who do not in terms of the size of primary tumor and the incidence of metastatic lesion lymph nodes at detection [15,16]. Also the Shanghai randomized trial demonstrated no significant stage shift or mortality reduction from breast cancer after 5 to 10 years of follow-up in the BSE group compared to controls $[17,18]$. Similarly a literature review on the topic indicated no benefit from routine BSE instruction as a screening tool for breast cancer [19]. However, despite continuous debate about the efficacy of BSE $[20,21]$, it seems that breast self-examination not as a public health policy but as a preventive measure remains a method of choice for early detection of breast cancer in developing countries. Resource constraints in low and middleincome regions lead to limited application of established guidelines for breast health care in developed countries [22].

To summarize it should be noted that in fact none of the above modalities for breast cancer screening could be regarded as the best method for early detection and mortality reduction. These approaches have their own potential benefits and harms. Thus, at present the emphasis is to raise breast cancer awareness among women to overcome ever-increasing burden of the disease. It appears that over- 
all the best way to save women's life is to make them aware of the potential benefits and harms of these approaches and to raise their knowledge about the warning signs of breast cancer. At present in addition to public health professionals, even oncologists advise breast awareness over routine breast self-examination [23]. However, one should not confuse between breast cancer awareness and breast self-examination since these are not the same. Breast cancer awareness can be defined as 'a woman becoming familiar with her own breasts and the way that they will change throughout her life' [24].

Breast cancer awareness programmes have been very successful at several grounds including creation of greater compliance with breast cancer prevention and screening strategies [25]. However, women with different cultures vary in their views about breast cancer and about preventive strategies [26]. This paper reports data from Iran (a culturally diverse population) on women's knowledge about breast cancer and their breast self-examination behaviors.

\section{Methods}

As part of a population-based randomized trial on different invitation methods for attending breast care classes in Tehran, a study was conducted to investigate Iranian women's views about breast cancer and their self-reported practice of BSE. The ethics committee of the Iranian Centre for Breast Cancer approved the study.

The study carried out in one of the central districts of Tehran that has five divisions with a total population of 310184 and was chosen because the district has a mixed population. The study population consisted of female population of aged 20 to 80 years $(n=117679)$. A cluster sampling was applied to include an enough sample size from each district's division in the study. Assuming that at best $40 \%$ of the women would perform BSE, it was calculated that a sample of 280 women aged 20 to 80 years from each division (a total of 1400 female) would allow detecting a $20 \%$ difference between performer and nonperformer at $5 \%$ significance level. A study of this size has a power of $90 \%$.

Data were collected via a structured questionnaire derived from the literature and our own previous studies [27-30]. A trained female nurse interviewed each respondent. An informed consent was obtained before conducting the interviews. The questionnaire consisted of 15 items on demographic characteristics, history of personal breast problems, family history of breast cancer, knowledge about breast cancer covering its symptoms, the screening methods and practice of BSE [Additional file 1]. Analysis included descriptive statistics and the Chi-squared test where necessary.

\section{Results}

In all 1402 women were studied. The mean age of the respondents was 43.4 ( $\mathrm{SD}=14.4$ ) years and most were married $(85 \%)$. Ninety-four percent of the respondents indicated that "they did not have any personal breast disease" while the remaining 6\% reported that "they had benign (5\%) and malignant breast disease (1\%)". The positive family history of breast cancer reported by $10 \%$ of women $(n=138)$. Of those with a family member with breast cancer $(n=138), 36 \%(n=50)$ reported that their first-degree relatives (mother, sister and daughter) had breast cancer and the remaining $64 \%(n=88)$ reported of the existence of breast cancer in their other family members. The demographic characteristics of the respondents are shown in Table 2.

When the respondents were asked about breast cancer in Iran, 64\% ( $n=894)$ said that "they have heard about the disease" and 61\% $(\mathrm{n}=851)$ believed that "breast cancer is relatively a common disease among women in Iran". The respondents' knowledge of breast cancer symptoms was also studied. Most women (44\%) perceived a painless mass as a breast cancer symptom.

Overall the study findings indicated that $61 \%$ of the respondents knew about breast cancer screening methods:

Table 2: Demographic characteristics of the study sample (1402)

\begin{tabular}{lll}
\hline & Number & $\%$ \\
\hline Age groups (years) & & \\
$20-29$ & 258 & 18 \\
$30-39$ & 354 & 25 \\
$40-49$ & 334 & 24 \\
$50-59$ & 220 & 16 \\
$60>$ & 236 & 17 \\
Mean (SD) & $43.4(14.4)$ & \\
Range & $20-80$ & \\
\hline Educational status & & \\
Primary education & & 48 \\
Secondary education & 673 & 35 \\
Higher education & 497 & 17 \\
\hline Marital status & 232 & \\
Single & & 8 \\
Married & 117 & \\
Widowed/divorced & 1183 & 85 \\
\hline Personal history of breast problems & 102 & 7 \\
Yes & & \\
No & 84 & 6 \\
\hline Family history of breast cancer & 1318 & 94 \\
Yes & & \\
No & 138 & \\
\hline
\end{tabular}


$31 \%$ knew about breast self-examination, 21\% about clinical examination and $9 \%$ about mammography. The remaining 39\% claimed that they know nothing about breast cancer screening methods. Most respondents (48\%) said that electronic media (television 34\% and radio $14 \%$ ) were their source of information.

When the respondents were asked about breast self-examination, $37 \%(n=520)$ reported that 'they practice breast self-examination'. Only $17 \%$ of women said that 'they do regular breast self-examination'. When it was investigated to find out women's reasons for not doing breast selfexamination, $64 \%$ claimed that 'they do not know how to do it'. Table 3 shows the respondents' knowledge of breast cancer and self-reported practice of breast self-examination.
Further analysis of the data carried out to investigate about the relationship between the performance of breast self-examination and demographic and other studied variables. The findings indicated that performing breast selfexamination is significantly related to: age $\left(\chi^{2}=28.9, \mathrm{P}=\right.$ $0.00006)$, marital status $\left(\chi^{2}=10.3, \mathrm{P}=0.03\right)$, education $\left(\chi^{2}=73.1, \mathrm{P}<0.00001\right)$, knowledge about breast cancer $\left(\chi^{2}=153.4, \mathrm{P}<0.00001\right)$, and knowledge about breast cancer screening programs $\left(\chi^{2}=254.9, \mathrm{P}<0.00001\right)$, but not to personal $\left(\chi^{2}=3.4, \mathrm{P}=0.2\right)$ and family $\left(\chi^{2}=0.2, \mathrm{P}\right.$ $=0.7$ ) history of breast problems. In fact the results suggest that women aged 40 to 59 , married, with higher education and more informed about breast cancer were more likely to perform BSE.

Table 3: Respondents' knowledge of breast cancer and self-reported practice of breast self-examination $(n=1402)$

\begin{tabular}{|c|c|c|}
\hline & Number & $\%$ \\
\hline \multicolumn{3}{|l|}{ Have you heard about breast cancer in Iran? } \\
\hline Yes & 894 & 64 \\
\hline No & 508 & 36 \\
\hline \multicolumn{3}{|l|}{ What do you think about breast cancer in Iran } \\
\hline It is a rare disease among women & 200 & 14 \\
\hline It is relatively a common disease among women & 851 & 61 \\
\hline I don't know & 351 & 25 \\
\hline \multicolumn{3}{|l|}{ Breast cancer symptoms } \\
\hline Painless mass & 618 & 44 \\
\hline Painful mass & 183 & 13 \\
\hline Nipple retraction & 72 & 5 \\
\hline Breast pain & 223 & 16 \\
\hline Breast discharge & 81 & 6 \\
\hline Bloody discharge & 118 & 8 \\
\hline Breast asymmetry & 20 & 2 \\
\hline Don't know & 87 & 6 \\
\hline
\end{tabular}

\section{Knowledge about screening programs*}

Heard of BSE

Heard of clinical examination

Heard of mammography

Knew nothing

Source of information*
Radio
Television
Printed materials
Friends
Others (physicians, family, etc.)

\section{Frequency of self-reported BSE}

Regularly (monthly)

Occasionally

Never

$\begin{array}{ll}505 & 31 \\ 337 & 21 \\ 144 & 9 \\ 626 & 39\end{array}$

\footnotetext{
* The respondent could choose more than one response category. The percentages are based on total responses and not total number of the respondents.
} 


\section{Discussion}

This population-based study carried out to investigate about Iranian's female knowledge of breast cancer and their BSE practicing behavior. The study sample was relatively a representative sample of the study population except in marital status (with a larger proportion of married women) and in education (with a smaller proportion of educated people). This was due to the fact that basically Iran has a young population (about 50\%) and that the younger age females (mostly single and educated) were not included in the study.

In this study $64 \%$ of respondents said that they knew about breast cancer and $17 \%$ of whole sample indicated that they were performing regular monthly BSE. Lower rates of BSE performance have reported from developing countries. A study from Saudi Arabia found that only $30.3 \%$ of the women had heard about breast self-examination and $18.7 \%$ reported they practiced BSE within the previous year [31]. Another study from Nigeria demonstrated that women lacked enough knowledge about breast cancer and only $34.9 \%$ claimed to ever-practiced BSE [32]. While a study of BSE behavior among Chinese immigrant women living in San Francisco indicated that $80.9 \%$ reported having heard of BSE but only $53.9 \%$ of the women had performed BSE during the past year [33]. Comparing the figures with that of developed countries clearly suggests that there are obvious differences. It has been shown that $75 \%$ of the women conduct BSE in the United States and its adequate quality was rated in $27 \%$. Also higher duration, frequency and quality of BSE were predictors of further diagnostic investigations [34]. Similarly an Austrian study reported that about $31 \%$ of women examined their breasts thoroughly [35].

Although 'painless mass' was the most reported symptom of breast cancer by women, the study results indicated that women had inadequate knowledge about this breast cancer symptom. Only $44 \%$ of women said that painless lump is a common symptom of breast cancer. The remaining 46\% indicated that they 'don't know'. The figures even were lower for other symptoms. For instance, only a few proportions of women knew that nipple retraction (\%5) and bloody discharge (6\%) are warning signs of breast cancer. About screening programmes the awareness knowledge was also very inadequate: only $21 \%$ and $9 \%$ have respectively heard about breast clinical examination and mammography. This is consistent with other studies from developing countries and women from minority ethnic groups $[32,36]$, whereas a study from U.K indicated that $70 \%$ of women were well aware of 'painless lump' and able to identify these symptoms in their breast selfexamination [37]. A recent publication from U.K reported a significant lack of the prerequisite knowledge and confi- dence to detect a breast change among older women aged 63 to 73 years [38].

However although cultural differences might contribute to such variations, the role of some other underlying factors on breast health awareness in women should not be neglected. Studies have shown that formal training programs have profound effects on regular BSE performance with a correct technique $[39,40]$. A study from Turkey showed that theoretical educations on breast cancer awareness and BSE training were effective even in illiterate and low-educated women [41].

The main sources of information about breast cancer were 'mass media' (48\%) and followed by friends (20\%). In most developing countries mass media are governed by the 'states' and using them would help to increase awareness about breast cancer. Usually due to some religious and cultural reasons such programs receive less attention in public media. Furthermore a very low proportion of women indicated that they have received any information from their doctors. Indeed many women (64\% of non performers) stated that they 'do not know how to do BSE'. Primary health care professionals would play an important role in conveying correct information regarding breast cancer [42]. It is argued that ignorance regarding incidence, outcome and risk of breast cancer makes it unlikely that at risk females could currently make informed decisions on a range of breast issues [43].

Statistical analysis indicated that performing BSE was significantly related to age, marital status, education, knowledge of breast cancer and its screening programs. It has been shown that women with less formal education more likely had inadequate knowledge about breast cancer that inversely influenced their breast cancer screening behaviors [44]. Another study based on health belief model showed intentions to do BSE among Turkish women is associated with "informed about breast cancer and having health insurance" [45].

This study did not show a significant association between personal and family history of breast cancer and performing BSE as compared to women without personal and family history of breast problems. In contrast, studies have shown that women with a family history of breast cancer may perform excessive BSE. Designing appropriate interventions would enhance the women's confidence in their ability to do BSE effectively and reduce worries regarding their breast cancer risk [46]. However, since women having any breast problems are expected to be different in their perceptions, knowledge and attitude from those having benign or malignant breast diseases, the future studies should include only women without any breast problems. 


\section{Conclusion}

Although this descriptive study has its own limitations, for the first time it provides useful information that could be utilized by both researchers and those involved in public health programmes. The findings indicated that the women awareness of breast cancer warning signs (painless lump, retraction of nipple, and bloody discharge) and effective screening methods i.e. clinical examination, and mammography were very inadequate. Thus, health education programmes to rectify the lack of women awareness is urgently needed. Indeed the focus of primary health care providers should be to raise awareness about breast care among women and to encourage them to report any unusual changes in their breasts to their family or care physicians.

\section{Abbreviations \\ BSE: Breast Self Examination}

\section{Competing interests}

The authors declare that they have no competing interests.

\section{Authors' contributions}

AM designed the study, analyzed the data and wrote the paper. MV contributed to the data entry, literature review and writing-up process. IH and AMH contributed to the study design and analysis. AS contributed to the data collection and the data entry. FK, ME, SH and SJ contributed to the study design and helped in writing the manuscript. All authors read and approved the final manuscript.

\section{Additional material}

\section{Additional File 1}

Breast cancer: knowledge, screening methods and breast self-examination survey. This is a short questionnaire assessing women awareness on breast cancer and its screening methods. It also asks whether women perform breast self-examination or not.

Click here for file

[http://www.biomedcentral.com/content/supplementary/1447056X-7-6-S1.doc]

\section{Acknowledgements}

The early analysis of this study was appeared in Cancer Strategy. It is no longer exists.

\section{References}

I. Parkin DM, Bray F, Ferlay J, Pisani P: Global cancer statistics, 2002. CA Cancer J Clin 2005, 55(2):74-108.

2. Wilson CM, Tobin S, Young RC: The exploding worldwide cancer burden: the impact of cancer on women. Int J Gynecol Cancer 2004, | 4: I- I I.

3. World Health Organization: Cancer. [http://www.who.int/media centre/factsheets/fs297/en]. accessed 30.07.2008

4. Harirchi I, Ebrahimi M, Zamani N, Jarvandi S, Montazeri A: Breast cancer in Iran: a review of 903 case records. Public Health 2000 , | | 4: |43-| 45.
5. Mousavi SM, Montazeri A, Mohagheghi MA, Mousavi Jarrahi A, Harirchi I, Najafi M, Ebrahimi M: Breast cancer in Iran: an epidemiological review. Breast J 2007, I 3:383-39I.

6. Ministry of Health and Medical Education: Iranian Annual National Cancer Registration Report 2005-2006. Ministry of Health and Medical Education, Office of Deputy Minister for Health, Center for Disease Control and Prevention, Cancer Office: Tehran, Iran 2007.

7. Elmore JG, Armstrong K, Lehman CD, Fletcher SW: Screening for breast cancer. JAMA 2005, 293:|245-1256.

8. Gotzsche PC, Nielsen M: Screening for breast cancer with mammography. Cochrane Database Syst Rev 2006. Art No.: CD001877

9. Miller $A B$, To $T$, Baines $C$, Wall $C$ : The Canadian National Breast Screening Study- I: breast cancer mortality after I I to I 6 years of follow-up. A randomized screening trial of mammography in women age $\mathbf{4 0}$ to $\mathbf{4 9}$ years. Ann Intern Med 2002, I37(5 Part I):305-3 I2.

I0. Mittra I, Baum M, Thornton $\mathrm{H}$, Houghton J: Is clinical breast examination an acceptable alternative to mammographic screening? $B M / 2000,321: 107 \mid-1073$.

II. Weiss NS: Breast cancer mortality in relation to clinical breast examination and breast self-examination. Breast $J$ 2003, 2(Suppl):S86-S89.

12. Jatoi I: Screening clinical breast examination. Surg Clin North Am 2003, 83:789-80I.

13. Ellman R, Moss SM, Coleman D, Chamberlin J: Breast self-examination programmes in the trial of early detection of breast cancer: ten years findings. $\mathrm{Br} J$ Cancer I993, 68(I):208-2I 2 .

14. Lam WW, Chan CP, Chan CF, Mak CC, Chan CF, Chong KW, Leung $\mathrm{MH}$, Tang $\mathrm{MH}$ : Factors affecting the palpability of breast lesion by self-examination. Singapore Med ] 2008, 49(3):228-232.

15. Semiglazov VF, Sagaidak VN, Moiseyenko VM, Mikhailov EA: The role of breast self-examination in early breast cancer detection (results of the 5-years USSR/WHO randomised study in Leningrad). Eur J Epidemiol 1992, 8:498-502.

16. Semiglazov VF, Sagaidak VN, Moiseyenko VM, Mikhailov EA: Study of the role of breast self-examination in the reduction of mortality from breast cancer. The Russian Federation/World Health Organization Study. Eur J Cancer 1993, 29:2039-2046.

17. Thomas DB, Gao DL, Ray RM, Wang WW, Allison Cl, Chen FL, Porter P, Hu YW, Zhao GL, Pan LD, Li W, Wu C, Coriaty Z, Evans I, Lin MG, Stalsberg H, Self SG: Randomized trial of breast self-examination in Shanghai: methodology and preliminary results. J Natl Cancer Inst 1997, 89:355-365.

18. Thomas DB, Gao DL, Ray RM, Wang WW, Allison Cl, Chen FL, Porter P, Hu YW, Zhao GL, Pan LD, Li W, Wu C, Coriaty Z, Evans I, Lin MG, Stalsberg H, Self SG: Randomized trial of breast self-examination in Shanghai: final results. I Natl Cancer Inst 2002 , 94( I 9): |445-| 457 .

19. Baxter N, Canadian Task Force on Preventive Health Care: Preventive health care, 200 I update: should women be routinely taught breast self-examination to screen for breast cancer? CMAI 200I, I 64(13): 1837-1846.

20. Hachshaw AK, Paul EA: Breast self-examination and death from breast cancer: a meta-analysis. Br J Cancer 2003, 88: I 047-I 053.

21. Shen Y, Yang Y, Inoue LY, Munsell MF, Miller AB, Berry DA: Role of detection method in predicting breast cancer survival: analysis of randomized screening trials. I Natl Cancer Inst 2005 , 97( 16): I 195-1203.

22. Anderson $B O$, Jakesz $R$ : Breast cancer issues in developing countries: an overview of the Breast Health Global Initiative. World J Surg 2008, 32:2578-2585.

23. Hampton $T$ : Oncologists advise breast awareness over routine breast self-examination. JAMA 2008, 300:1748-1749.

24. Thornton H, Pillarisetti RR: 'Breast awareness' and 'breast selfexamination' are not the same. What do these terms mean? Why are they confused? Eur J Cancer 2008, 44:21 I8-2I II.

25. Anonymous: Breast cancer awareness: too much of a good thing? Lancet Oncol 2007, 8: I04I.

26. Smigal C, Jamal A, Ward E, Cokkinides V, Smith R, Howe HL, Thun $M$ : Trends in breast cancer by race and ethnicity: update 2006. CA Cancer J Clin 2006, 56(3): I68-I83.

27. Baum M: Patient's perception of risk and breast cancer awareness. Br J Radiol 1997, 70:777-78I. 
28. Grunfeld EA, Ramirez AJ, Hunter MS, Richards MA: Women's knowledge and beliefs regarding breast cancer. $\mathrm{Br} J$ Cancer 2002, 86: $1373-1378$.

29. Haji-Mahmoodi M, Montazeri A, Jarvandi S, Ebrahimi M, Haghighat S, Harirchi I: Breast self-examination: knowledge, attitudes and practice among female health care providers in Tehran, Iran. Breast J 2002, 8:222-225.

30. Jarvandi S, Montazeri A, Harirchi I, Kazemnejad A: Beliefs and behaviours of Iranian teachers toward early detection of breast cancer and breast self-examination. Public Health 2002, I | 6:245-249.

3I. Jahan S, Al-Saigul AM, Abdelgadir MH: Breast cancer. Knowledge, attitudes and practices of breast self examination among women in Qassim region of Saudi Arabia. Saudi Med J 2006, 27(I I): |737-I74I.

32. Okobia MN, Bunker CH, Okonofua FE, Osime U: Knowledge, attitude and practice of Nigerian women towards breast cancer: a cross-sectional study. World J Surg Oncol 2006, 4: I I.

33. Wong-Kim E, Wang CC: Breast self-examination among Chinese immigrant women. Health Educ Behav 2006, 33:580-590.

34. Tu SP, Reisch LM, Taplin SH, Kreuter W, Elmore JG: Breast selfexamination: self-reported frequency, quality and associated outcomes. J Cancer Educ 2006, 2 I: I75- I8I.

35. Janda M, Obermair A, Haidinger G, Waldhoer T, Vutuc C: Austrian women's attitudes toward and knowledge of breast selfexamination. J Cancer Educ 2000, I 5(2):91-94.

36. Schettino MR, Hernandez-Valero MA, Moguel R, Hajek RA, Jones LA: Assessing breast cancer knowledge, beliefs and misconceptions among Latinas in Houston, Texas. J Cancer Educ 2006 2 I :S42-S46.

37. Grunfeld EA, Ramirez AJ, Hunter MS, Richard MA: Women's knowledge and beliefs regarding breast cancer. $\mathrm{Br} J$ Cancer 2002, 86: I373-I378.

38. Linsell L, Burgess CC, Ramirez AJ: Breast cancer awareness among older women. Br J Cancer 2008, 99: I 22 I- I 225.

39. Janda M, Stanek C, Newman B, Obermair A, Trimmel M: Impact of videotaped information on frequency and confidence of breast self-examination. Breast Cancer Res Treat 2002, 73:37-43.

40. Sorensen J, Hertz A, Gudex C: Evaluation of a Danish teaching program in breast self-examination. Cancer Nurs 2005, 28(2): $|4|-\mid 47$.

4I. Budakoglu II, Maral I, Ozdemir A, Bumin MA: The effectiveness of training for breast cancer and breast self-examination in women aged 40 and over. J Cancer Educ 2007, 22(2): I08-III.

42. Avci IA, Ozcan A, Altay B, Cavusoglu F: The problems encountered by midwives during breast self-examination training. Eur J Oncol Nurs I 2(4):329-333.

43. McMenamin M, Barry $H$, Lennon AM, Purcell $H$, Baum M, Keegan D, McDermott E, O'Donoghue $D$, Daly $L$, Mulcahy $H$ : A survey of breast cancer awareness and knowledge in a western population: lots of light but little illumination. Eur J Cancer 2005, 41:393-397.

44. Webster P, Austoker J: Women's knowledge about breast cancer risk and their views of the purpose and implications of breast screening- a questionnaire survey. J Public Health 2006, 28:197-202.

45. Nahcivan NO, Secginli S: Health beliefs related to breast selfexamination in a sample of Turkish women. Oncol Nurs Forum 2007, 34:425-432.

46. Norman P, Brain K: An application of an extended health belief model of the prediction of breast self-examination among women with a family history of breast cancer. $\mathrm{Br} J$ Health Psychol 2005, 10:1-16.
Publish with Biomed Central and every scientist can read your work free of charge

"BioMed Central will be the most significant development for disseminating the results of biomedical research in our lifetime. "

Sir Paul Nurse, Cancer Research UK

Your research papers will be:

- available free of charge to the entire biomedical community

- peer reviewed and published immediately upon acceptance

- cited in PubMed and archived on PubMed Central

- yours - you keep the copyright

Submit your manuscript here:

http://www.biomedcentral.com/info/publishing_adv.asp
BiolMedcentral 